\title{
Single-item recognition following a verbal discrimination study trial
}

\author{
DONALD H. KAUSLER, EDWARD J. PAVUR, JR., and ROBERT M. YADRICK \\ University of Missouri, Columbia, Missouri 65201
}

\begin{abstract}
A verbal discrimination (VD) study phase was followed by a single-item (i.e., one item at a time) test phase. Prior right $(R)$ items from the VD list were found to have higher old-new hit rates on the test phase than prior wrong (W) items. However, prior $\mathrm{W}$ items had higher hit rates than prior $R$ items in terms of recognition of their intrapair function. These results were interpreted in terms of a high criterion model whereby an old test item must prossess a large number of frequency units before it is identified as being $R$. In addition, false recognition effects were demonstrated for new test items that were homophones of prior $R$ items, but not for new test items that were homophones of prior $W$ items. These results were interpreted in terms of a feature analytic extension of frequency theory.
\end{abstract}

Both Erlebacher, Hill, and Wallace (1967) and Radtke and Foxman (1969) compared postcriterial recognition for wrong (W) and right (R) items on a verbal discrimination (VD) task, and found recognition to be substantially higher for R than for W items (e.g., $99 \%$ vs $87 \%$ in the Erlebacher et al study). Recognition in these studies simply required old-new discriminations for old items ( $R$ and $W$ ) and new items. A correlated, but unexplored, question concerns S's further ability to discriminate between old items on the basis of their intrapair function (i.e., $R$ or $W$ ). The present study introduced a methodology for testing the accurdcy of functional, as well as old-new, discriminations. The Ss were given a standard study phase on a VD list and then a test phase in which items were exposed individually. Some of the test items were new (i.e., were not in the prior VD list) while the other items were either old $R$ items or old $\mathrm{W}$ items. The $\mathrm{S}$ then decided whether they had functioned previously as $\mathrm{R}$ or $\mathrm{W}$ in the VD list.

Predictions from frequency theory (Underwood, 1972) are clear regarding the effect of prior intrapair function on old item recognition. Old-new discriminations are based on the presence of situational response frequencies to old items, but not to new. Since the average number of units accrued to $\mathrm{R}$ items is greater than that for $W$ items, discriminability from zero situational frequency should be greater for $R$ than for $W$ items. The earlier item recognition studies agree with this prediction, and there is no reason to predict otherwise in the single trial situation.

Recognition of prior intrapair function presents a less clear, but more interesting, case in terms of predictions from frequency theory. According to the theory (Ekstrand, Wallace, \& Underwood, 1966), the cues for R-W discriminations are purely quantitative. $\mathrm{R}$ items are responded to more frequently during study phases than are $\mathrm{W}$ items, yielding intrapair disparities as cues for selecting $\mathrm{R}$ item components. The identification of an old item's prior function must be based on similar quantitative cues. An obvious cue for a given item is the number of frequency units accrued to that item. Since $R$ items are responded to more frequently than $\mathrm{W}$ items, the distribution of item frequency units should be dispersed around a greater mean value for the former than for the latter set of items, as illustrated in Fig. 1. Presumably, items in both distributions that exceed some low criterion value are identified as being old (see Fig. 1). The displacement of the $\mathrm{R}$ item distribution to a greater mean value would account for the larger old-new hit rate expected for these items.

A reasonable assumption is that an additional criterion, set higher than the old-new criterion, mediates identification of prior item function. A test item whose frequency units exceeded this value would be identified as "old item, prior R function." On the other hand, a test item whose number of units fell below this value, but exceeded that of the lower criterion used to evaluate the old-new dimension, would be identified as "old item, prior $\mathrm{W}$ function." The relative hit rates for $\mathrm{R}$ and $\mathrm{W}$ items would be contingent upon where Ss set their higher criterion. If the criterion is set at a high absolute value (left panel of Fig. 1), few $R$ items would exceed this value, and consequently, a large proportion of them would be misidentified as being W. By contrast, most W items fall below the criteion (See Fig. 1), and should be correctly identified as being $\mathrm{W}$. If the criterion is set at a moderate absolute value (right panel of Fig. 1), the hit rate for prior $\mathrm{R}$ items is likely to be greater than that for $\mathrm{W}$ items. Most $\mathrm{R}$ items exceed this value, and should be correctly identified as being $R$. Many $W$ items also exceed this value, and should be incorrectly identified as being $R$. As a test of these alternatives, the present study provides differential base rates for correct $R$ versus correct $\mathrm{W}$ item identification.

An additional innovation was the inclusion of a procedure analogous to that employed in single-item recognition learning research to detect false recognition effects (Underwood, 1965). The extension called for new test items that were related either to prior $\mathrm{R}$ items or to prior $\mathrm{W}$ items, thereby providing a further test of a 


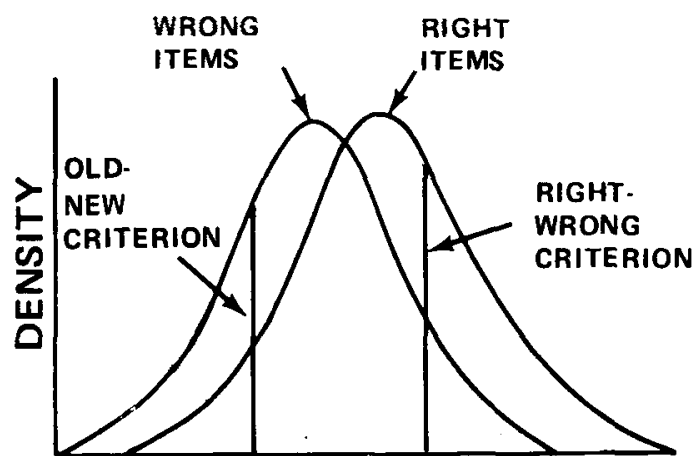

FREQUENCY UNITS

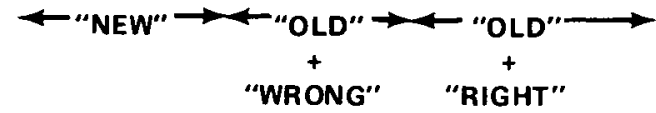

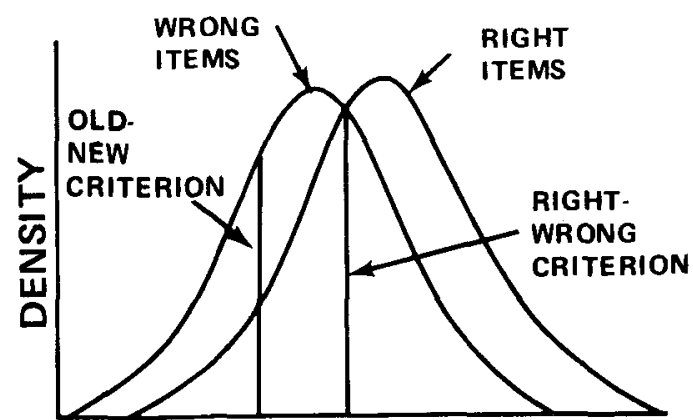

FREQUENCY UNITS

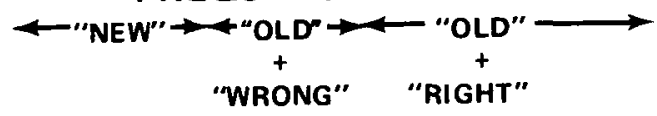

Fig. I. Hypothetical distributions of the number of frequency units for $\mathrm{W}$ and $\mathrm{R}$ items. Two criteria are established for decision making, one for old-new decisions (lower criterion in both panels) and the other for $R-W$ decisions (high absolute value in the left panel and moderate absolute value in the right panel.)

feature analytic modification of frequency theory (Kausler, 1974). The modification postulates that semantic and sensory features of items are tagged by frequency-of-response cues. Features of $R$ items have greater probabilities of being tagged than features of $W$ items. Consequently, new test items sharing features with prior $\mathrm{R}$ items are more likely to be falsely recognized as old than are new test items sharing features with prior $W$ items. Feature sharing was manipulated by the use of homophone word pairs of either low or high orthographic distinctiveness as study item-new test item combinations. The false recognition rate for homophones of low distinctiveness was expected to be especially pronounced. In this case, the overlap between old and new items involved visual features, as well as the complete overlap of aural features. Distinctiveness is known to have a potent effect on standard VD learning (Kausler, 1973).

Finally, the present study was conducted as two independent experiments that differed only in the rate of exposing pairs during the single study phase $-3 \mathrm{sec}$ per pair in Experiment $I$ and $6 \mathrm{sec}$ in Experiment II. Experiment Il was added following the failure to demonstrate a false recognition effect in Experiment $I$ for either $\mathbf{R}$ or $\mathbf{W}$ items. Increasing study time should increase especially the number of respones to $R$ items through additional rehearsal opportunity, thereby enlancing the likelihood of inducing subsequent false recognitions.

\section{METHOD}

\section{General Description and Design}

The format of both experiments called for the presentation of 25 pairs in the study phase and 50 individual jtems in the test phase. Of the study pairs, five were fillers (i.e., their item components were not included in the test phase) inserted in the first two and the last three input positions. Each of the remaining 20 study pairs was composed of a homophonic word and a nonhomophonic word (e.g., steal-flash). All 20 nonhomophones were included as subsequent test items. For a given S, 10 of the nonhomophones had functioned as Study $R$ items and 10 as Study W items. Ten of the homophones were also carried over to the test phase. For a given $S$, five of these homophones had been prior $R$ items and five prior $W$ items. Thus, the test phase contained 30 old items for every S. Each of the remaining 10 homophonic study words had its phonemic mate (e.g., steel for steal) included as a new test item. For a given $S$ five of the study homophones had been $R$ items, and five had been $\mathrm{W}$ items. Finally, a control test item (matched for preexperimental frequency, number of syllables, and grammatical form class) was included for each of the 10 homophonic test items. Thus, the test phase contained 20 new items for every S-10 experimental (i.e., related to prior study items) and 10 control counterparts.

Several distinctive features characterized the design of the two experiments. First, each nonhomophonic test item $(n=20)$ occurred as both a $R$ item and a $W$ item during the prior study phase. That is, for half of the Ss, a given test item had been a prior $\mathrm{R}$ tiem; for the other half, the same item had been a prior $W$ item. Second, each homophone $(n=20)$ occurred equally of ten in its old study form (e.g., steal) and its new, but related, form (e.g., steel) during the test phase. That is, for half of the Ss, a given test item had been a prior study item; for the other half, the comparable test item was the homophonic mate. Third, each homphone occurred as both a $\mathrm{R}$ item and a $\mathrm{W}$ item during the study phase.

Implementation of the complete design required four independent groups of Ss per experiment. For Groups 1 and 2, 10 of the nonhomophones, identified as Set A (randomly assigned), functioned as Study $\mathrm{R}$ items, and 10 , identified as Set $B$, functioned as Study $W$ items. For Groups 3 and 4 , the items of Sets $A$ and $B$ reversed $R$ and $W$ functions. In addition, possible confounding effects resulting from left vs right spatial positioning of intrapair study items were controlled by dividing Sets $A$ and $B$ into random subsets of 5 items each (Sets Al and $A 2$ and Sets B1 and B2). Groups 1 and 3 had the it ems from Sets $A 1$ and $B 1$ exposed on the spatial left, and the items from Sets $A 2$ and B2 on the spatial right. These set-position combinations were reversed for Groups 2 and 4 . In a similar manner, 10 of the homophones were assigned to Set $\mathrm{C}$ and 10 to Set D. For Groups 1 and 2 Set $C$ members continued on as old items in the test phase, and Set D members were replaced by their homophonic mates. For Groups 3 and 4 the set-item placement combinations 
were reversed. Spatial position effects were again controlled by having the left-positioned items of Group 1 become the right-positioned items of Group 2, the left-positioned items of Group 3 become the right-positioned items of Group 4, etc. Later analyses revealed, however, that spatial position had little effect on any of the dependent variables employed in this study, either as a main effect or an an interacting variable. An additional independent varaible incorporated into this aspect of the design was that of orthographic distinctiveness. Five members of both Set $C$ and Set D had low orthographic distinctiveness with respect to their homophonic mates (mean ratings $<3.05$ in Olson and Kausler's (1971) norms). The remaining 5 members of both sets had high orthographic distinctiveness with respect to their homophonic mates (mean ratings $>5.91$ ).

\section{Subjects}

The Ss were students in undergraduate psychology classes, 73 in Experiment $I$ and 69 in Experiment II. All were naive with respect to prior participation in recognition learning research. They were assigned randomly to four groups in each experiment, with near equality in both group size and sex composition. All of the Ss in a given group were tested simultaneously.

Words

The 20 nonhomophones were all words of high preexperimental frequency (A or AA in the Thorndike-Lorge, 1944, norms). They were, as far as could be determined from existing word norms and the judgment of the Es, associatively unrelated to either each other or to the other words employed in these experiments. As noted previously, the 20 pairs of homophones were selected from Olson and Kausler's (1971) norms. Although the 40 words ranged in Thorndike-Lorge count from two per million words to AA, they were predominantly of high frequency (A or AA). Each of the 20 control words ( 10 employed for Groups $I$ and 2 and 10 for Groups 3 and 4) was selected from the Thorndike-Lorge norms on the basis of matching its experimental counterpart in frequency, number of syllables, and form class. Care was again taken to assure the absence of associative relatedness between each word and all other words in the study and test phases.

\section{Procedure}

Each group was instructed at the beginning of the study phase as to the general nature of a VD learning task. The instructions included a study-test cycle in which: (1) every study pair has one item underlined to identify it as $R$; (2) the $R$ item is on the spatial left for some pairs and on the spatial right for other pairs; (3) the test phase has pairs in which the $R$ item is not specified and must be identified by S; and (4) the left-right spatial order of test pairs need not match that for prior study pairs. The instructions were supplemented by a two pair practice list demonstrating a study-test cycle. The groups were then informed that they would have a single study phase on a list of 25 pairs, followed by a test phase. The nature of the test phase was not described, but the implication, of course, was that it would follow the just described standard procedure. The word pairs were then exposed via a Carousel projector on a screen in clear view of all members of a group. The rate of exposure was $3 \mathrm{sec}$ per pair in Experiment 1 and $6 \mathrm{sec}$ in Experiment II. The 20 pairs of concern in this study were randomly assigned to Input Positions 3-22, with a different random order being employed for each group.

Immediately after the study phase, the groups were informed that their test phase would differ from the standard procedure They were told that they would view a series of individual words, some of which would be old in the sense of having been included in the study phase and the others new. They were asked to decide initially if a given word is "old" or "new" and then check the appropriate box on an answer sheet provided them. They were asked further to decide for each word identified as old whether it had been a $\mathbf{R}$ item or a $W$ item, and then check the appropriate box on the answer sheet. The test words were exposed at the rate of $10 \mathrm{sec}$ per item in both experiments. The input order of items was determined by random assignment, with a different random order being employed for each groups.

\section{RESULTS AND DISCUSSION}

\section{Old Vs New Item Recognition}

Hit rates were examined separately for $R$ vs $W$ nonhomophonic and $\mathrm{R}$ vs $\mathrm{W}$ homophonic old test items in each experiment. Individual words served as data points or "Ss" in these analyses and all other later analyses. The proportions of group members recognizing a given old item as "old" were determined separately for that item in its role as a prior $\mathrm{R}$ item and in its role as a prior $\mathrm{W}$ item. Mean hit rates were then computed for the 20 words within each category (the words, of course, were the same ones across $\mathrm{R}$ and $\mathrm{W}$ categories). Means for the various conditions are given in Table 1 .

The hit rate for prior $\mathrm{R}$ items was considerably higher than the hit rate for prior $W$ items in all four comparisons (see Table 1). Individual $t$ tests (correlated; arcsin transformations) revealed that the disparity was clearly significarii in each case: Experiment I, nonhomophones $[\mathrm{t}(19)=9.00, \mathrm{p}<.001]$; Experiment I, homophones $[\mathrm{t}(19)=6.27, \mathrm{p}<.001]$; Experiment II, nonhomophones $[\mathrm{t}(19)=6.83$, $\mathrm{p}<.001]$; Experiment II, homophones $[\mathrm{t}(19)=6.46$, $\mathrm{p}<.001]$. These re.ults confirm the fact that the disparity in hit rates found after multiple trials on a VD task (e.g., Erlebacher et al, 1967) is present even after only one study trial. Surprisingly, the increment in exposure rate from 3 to $6 \mathrm{sec}$ had little effect on improving the hit rate for either $\mathbf{R}$ or $\mathrm{W}$ items (see Table 1).

\section{Item Function Recognition}

Of concern here was the hit rate for identifying an item's prior $\mathrm{R}$ or W function, given initial recognition of

Table 1

Hit Rates for Old-New and Item Function Decisions in Experiments I and II

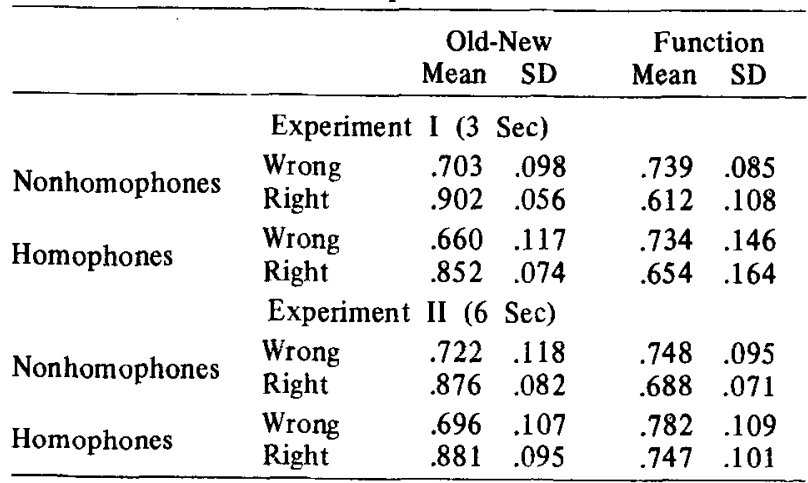


that item's oldness (i.e., a conditional probability). Hit rates were again examined separately for nonhomophonic and homophonic items in each experiment. Means for these conditional hit rates are given in Table 1.

For all four comparisons recognition of item function was greater for prior $\mathrm{W}$ items than for prior $\mathrm{R}$ items. Individual $t$ tests (correlated; arcsin transformations) revealed that the disparity attained significance for two of the comparisons: Experiment I, nonhomophones $[\mathrm{t}(19)=4.59, \mathrm{p}<.001] ;$ Experiment II, nonhomophones $[\mathrm{t}(19)=2.27, \mathrm{p}<.05]$. In addition, it approached significance for the remaining two comparisons: Experiment I, homophones $[t(19)=1.73$, $\mathrm{p}<.10]$; Experiment II, homophones $[\mathrm{t}(19)=1.78$, $p<.10]$. These results seem supportive of a "high criterion" model, that is, one in which a stringent level of frequency units is established for mediating R-W decisions. The differential hit rates may also be accounted for by a higher base rate for saying "wrong" than "right," given uncertainty as to item function. However, there are data available indicating little difference in these base rates. These data come from those new control items that were falsely identified as being "old" (proportions of .512 and .488 in Experiment I and .507 and .493 in Experiment II for W and $R$ classification, respectively).

In contrast to old-new hit rates, there was some indication of an improvement in item function hit rates as the rate of exposure increased from $3 \mathrm{sec}$ to $6 \mathrm{sec}$, especially for $\mathrm{R}$ items. The mean hit rates for all $\mathrm{R}$ items were .633 in Experiment $I$ and .718 in Experiment II; for $W$ items they were .736 and .765 . Unfortunately, the fact that exposure rate was confounded by the temporal separation of the two experiments prevented a statistical analysis of the specific effects of the rate variable.

The superior hit rate for $W$ items is difficult to reconcile with an alternative to frequency theory, the "tag and collapse'. or "paired-associate" hypothesis (cf. Eckert \& Kanak, in press; Medin, 1974). According to this hypothesis, intrapair discriminations are mediated by the acquisition of associative connections between $R$ item members and implicit "tags" signifying the correctness of these members. These associations are presumably elicited when $R$ items are presented individually in a test phase, thus enhancing their discriminability, relative to $\mathrm{W}$ items, as to being old. However, the elicitation of these associations should also enhance the detectability of item function for $R$ items, thus'enhancing their hit rate relative to $\mathrm{W}$ items. This clearly was not the case in this study. Furthermore, a signal detection analysis of the present data is consonant with a frequency interpretation. According to this interpretation, $d^{\prime}\left(d^{\prime}\right)$ for the distribution of $R$ item frequency units exceeds $d^{\prime}\left(d^{\prime} w\right)$ for the distribution of $\mathrm{W}$ item frequency units (relative, in both cases, to the mean of a "noise" distribution). Moreover, the
Table 2

False Recognition Rates for Experimental (E) and Control (C) Items in Experiments $I$ and II

\begin{tabular}{cccccc}
\hline \multicolumn{2}{c}{$\begin{array}{c}\text { Related } \\
\text { Study } \\
\text { Item }\end{array}$} & & \multicolumn{2}{c}{ Low } & \multicolumn{2}{c}{$\begin{array}{c}\text { High } \\
\text { Distinctiveness } \\
\text { Mean }\end{array}$} & \multicolumn{2}{c}{ SD } & Mean & SD \\
\hline \multicolumn{2}{c}{ Experiment I (3 Sec) } & & & & \\
\multirow{2}{*}{ Wrong } & E Items & .429 & .173 & .251 & .197 \\
& C Items & .451 & .190 & .281 & .159 \\
\multirow{2}{*}{ Right } & E Items & .536 & .140 & .264 & .199 \\
Experiment Il (6 Sec) & & & & & \\
\multirow{2}{*}{ Wrong } & E Items & .376 & .157 & .279 & .216 \\
\multirow{2}{*}{ Right } & C Items & .445 & .191 & .313 & .111 \\
& E Items & .478 & .187 & .200 & .149 \\
& C Items & .371 & .140 & .325 & .148 \\
\hline
\end{tabular}

magnitude of $d^{\prime}{ }_{R}-d^{\prime}{ }_{W}$ as estimated from old-new decisions should equal the magnitude as estimated from R-W decisions, in that both sets of values refer to the same distributions of $R$ and $W$ frequency units (but with different criteria for the two kinds of decisions; see Fig. 1). Estimates of $d_{R}^{\prime}$ and $d^{\prime} w$ required words that had been employed as both old ( $R$ and $W$ ) and new test items, a criterion satisfied by the present set of homphones. Only the analysis for Experiment II will be reported here (although the outcome was similar for Experiment $I, d_{R}^{\prime}-d^{\prime}{ }_{W}$ for $R \cdot W$ decisions failed to reach significance). For old-new decisions $\mathrm{d}^{\prime}{ }_{R}=1.835$ and $\mathrm{d}^{\prime} \mathrm{W}$ $=1.181$; for $\mathrm{R} \cdot \mathrm{W}$ decisions $\mathrm{d}_{\mathrm{R}}^{\prime}=1.355$ and $\mathrm{d}^{\prime}{ }_{\mathrm{W}}=.937$, with $d^{\prime}{ }_{R}-d^{\prime}{ }_{W}$ being significant in each case [comelated $\operatorname{ts}(19)=4.04, p<.01$, and $3.24, p<.01$, respectively] As expected, the disparity between the separately estimated $\mathrm{d}_{\mathrm{R}}^{\prime}-\mathrm{d}_{\mathrm{W}}^{\prime}$ values $(.236)$ fell far short of significance $[t(19)=1.28, p>.10]$. The tag and collapse principle seemingly predicts a greater $d_{R}^{\prime}-d^{\prime}{ }_{W}$ value for R-W decisions than for old-new decisions. This clearly was not found-if anything, the value was slightly greater for old-new decisions.

\section{False Recognition}

Means are given in Table 2 for the false recognition (i.e., falsely identifying new items as "old") rate under all conditions in both experiments. These rates were analyzed separately for Experiments I and II by means of 2 by 2 by 2 mixed analysis of variance (arcsin transformation) in which orthographic distinctiveness (low vs high) was a between-groups variable and item function (right vs wrong) and item type (experimental, or homophonic, vs control) were within-group variables.

For Experiment I only the main effect for orthographic distinctiveness attained statistical significance $[F(1,18)=17.35, p<.001]$. Both experimental items and their yoked control items displayed lower false recognition rates when the experimental relationship involved high distinctiveness 
than when it involved low distinctiveness (see Table 2). The effect of distinctiveness on yoked control items, as well as on experimental items, implies that the effect was due to some extraneous variable shared by the two classes of items. A likely candidate is the number of letters per item. The number of letters for most of the other items in the study and test phases was four. By contrast, the experimental items of high distinctiveness contained, for the most part, more than four letters (e.g., kernel). Since the control items were matched for number of syllables, they too were characterized by greater letter-length. The minority nature of the items within the two classes seemingly of fered a distinctive cue for recognizing their newness.

The main effect for distinctiveness was also significant in Experiment II $[F(1,18)=7.38, \mathrm{p}<.025]$. In addition, the Distinctiveness by Item Function by Item Type interaction effect attained significance $[F(1,18)=$ $6.18, p<.025]$. The nature of the interaction effect was explored by means of a series of correlated tests contrasting miss rates between experimental and control items. A higher miss rate for experimental than for control items defines, of course, the standard false recognition effect. This effect was clearly absent for $\mathrm{W}$ items of either low or high orthographic distinctiveness $[\operatorname{ts}(9)<1]$. On the other hand, there was a trend toward a false recognition effect for $\mathrm{R}$ items of low orthographic distinctiveness $[\mathrm{t}(9)=1.88, \mathrm{p}<.10]$. Interestingly, there was a significant reversal of the false recognition effect for $\mathrm{R}$ items of high orthographic distinctiveness $[t(9)=2.62, p<.05]$. That is, the miss rate for experimental items was significantly below the miss rate for their control counterparts (means of .200 and .325 , respectively).

The results for Experiment II are consistent with a feature analytic extension of frequency theory. The false recognition effect is seemingly contingent upon two factors: (1) the occurrence of a sufficient number of responses to study items to assure discriminable tags for their featural components (2) the presence of a substantial overlap between the features of the new items and those of prior study items. Considered together, these factors explain the fact that the standard false recogntion effect was found only for low distinctive homophones of prior $R$ items and then only in Experiment II. Here both prerequisites are satisfied by the extra rehearsal responses given $\mathbf{R}$ items that overlap both aurally and visually with test items. The reversal of the false recognition effect (i.e., a decrease in error rate relative to control words) for high distinctive homophones suggests that their untagged visual features provided salient cues for recognizing their newness, despite the complete overlap of their aural features with previously tagged aural features.

\section{REFERENCES}

Eckert, E., \& Kanak, N, J. Verbal discrimination learning: A review of the acquisition, transfer, and retention literature through 1972. Psychological Bulletin, 1974, 81, 582-607.

Ekstrand, B. R., Wallace, W. P.. \& Underwood, B. J. A frequency theory of verbal-discrimination learning. Psychological R eview, 1966, 73, 566-578.

Erlebacher, A., Hill, W. F., \& Wallace, W. P. Differential accural of frequency in verbal-discrimination learning. Journal of Verbal Learning \& Verbal Behavior, 1967, 6, 420-422.

Kausler, D. H. Orthographic distinctiveness of homonyms and the feature-tagging hypothesis. American Journal of Psychology, 1973, 86, 141-149.

Kausler, D. H. Continuity of processes across variants of recognition learning. In $R$. $L$. Solso (Ed.), Theories of cognitive psychology: The Loyola Symposium. Potomac: Lawrence Erlbaum Associates, 1974.

Medin, D. L. Frequency and coding responses in verbal discrimination learning. Memory \& Cognition, 1974, 2, 11-13.

Olson, G. A., \& Kausler, D. H. Orthographic distinctiveness of homonyms. Behavior Research Methods \& Instrumentation, $1971,3,298-299$.

Radtke, R. C., \& Foxman, J. Number of alternatives and similarity in verbal-discrimination learning. Journal of Verbal Learning \& Verbal Behavior, 1969, 8, 537-544.

Thorndike, E. L., \& Lorge, I. The teacher's word book of 30,000 words. New York: Teachers College Press, Columbia University, 1944.

Underw ood, B. J. False recognition produced by implicit verbal responses. Journal of Experimental Psychology, 1965, 70, 122-129.

Underwood, B. J. Word recognition memory and frequency information. Journal of Experimental Psychology, 1972, 94, 276-283.

(Received for publication A pril 19, 1974, revision received July $1,1974$. 